CPB Netherlands Bureau for Economic



CPB Discussion Paper | 314

Estimating the weight of opportunity costs in housing consumption

Machiel van Dijk 



\title{
Estimating the weight of opportunity costs in housing consumption
}

\author{
Machiel van Dijk*
}

CPB Netherlands Bureau for Economic Policy Analysis

P.O. Box 80510

2508 GM The Hague

The Netherlands

*Corresponding author (mfvd@cpb.nl)

\section{Highlights}

- Housing consumption lends itself well for empirically analyzing opportunity costs.

- I split up the user costs of housing in out-of-pocket and opportunity costs.

- Homeowners weigh in their opportunity costs at only 50 to 65 percent.

- It is unclear whether homeowners underestimate these costs or simply care less about them.

\begin{abstract}
People tend to neglect or underweight opportunity costs. Strong empirical evidence for the size of the underweighting appears to be absent. What are the weights people attach to opportunity costs relative to out-of-pocket costs? In this paper I estimate the weight of opportunity costs in probably the largest economic decision that households make: buying a house. I show that homeowners attach approximately twice as much weight to out-of-pocket costs of their housing consumption than to the opportunity costs associated with this.
\end{abstract}

Keywords: opportunity costs, out-of-pocket costs, housing

JEL classification: D11, D12, R21 


\section{Introduction}

Rational economic decision making requires explicit and implicit costs to be treated equivalently. Behaviorists ${ }^{1}$, on the other hand, argue that people attach more weight to explicit information that is easily available, such as out-of-pocket expenses, and hardly consider the implicit costs of outside options when making economic decisions. In order to understand actual economic behavior, knowing the weight that people attach to opportunity costs in real-life economic decisions is obviously key. Knowledge about the extent to which people systematically review the outside options in economic decision-making is essential not only for economic theorizing, but also for effective economic policy-making.

Unfortunately, the available behavioral research shows no clear consensus on this matter. Some claim that human decision makers only underweight opportunity costs (see, e.g., Thaler, 1980). Others, such as Frederick et al. (2009), argue that people even neglect them entirely. Moreover, the results of most of these studies are based on experimental research in a merely laboratory-like setting. Besides consensus in experimental research, strong empirical evidence based on real life empirical data thus appears to be largely absent as well.

Obviously, the lack of data on the actual size of the opportunity costs limits the scope for empirical research. Yet, there is one form of consumption that lends itself rather well to the empirical analysis of the weight of opportunity costs. As many households finance the purchase of their homes by a mixture of mortgage loans and private equity, the costs of housing consumption can well be divided into explicit cash flows, notably interest payments, and implicit opportunity costs of capital. Since buying a house is probably the largest economic decision that households make, analyzing the impact of opportunity costs on housing consumption may provide empirical evidence to what extent opportunity costs are underweighted in significant, real-life economic decision-making.

Based on household-level data on Dutch homeowners, this study aims to investigate the relevance of opportunity costs in housing consumption relative to the out-of-pocket expenditures related to housing. More precisely, the purpose here is to test the significance of the restriction that opportunity costs and out-of-pocket costs have the same weight in a simple model of housing demand. The analysis clearly rejects this hypothesis and shows that Dutch homeowners attach approximately twice as much weight to the out-of-pocket costs of their housing consumption than to the opportunity costs associated with this. These findings imply that opportunity costs are indeed significantly underweighted, but not completely neglected, in major, real-life economic decisions.

\footnotetext{
${ }^{1}$ Ashraf et. al (2005) show that Adam Smith already drew attention to the distinction between out-of-pocket and opportunity costs.
} 


\section{Methodology}

\subsection{Theoretical framework}

Housing consumption lends itself well, but not exclusively, to the empirical analysis of the weight of implicit costs (see, e.g., Stango and Zinman, 2009). Models of housing consumption often make use of the so-called user cost approach (Poterba, 1984). The user cost approach elegantly sets out the annual cost of housing consumption for an owner-occupier. User costs include mortgage interest payments, maintenance and repair costs, property taxes, depreciation and the opportunity costs of housing equity.

By adopting the user cost approach, housing costs can be rather easily divided into explicit out-of-pocket costs and implicit opportunity costs. For most households, the user costs of their housing consumption will be partly explicit and partly implicit. Interest payments and taxes are obviously explicit, whereas the opportunity costs of housing equity are much more implicit.

Implicit costs differ from explicit costs in two ways. First, implicit costs, such as the opportunity costs of housing equity, might be perceived as foregone gains, whereas explicit costs like monthly interest payments can be viewed as actual losses. As such, opportunity costs can be directly linked to prospect theory (Thaler, 1980). If the out-of-pocket costs of housing consumption are indeed viewed as losses and the opportunity costs of home equity are seen as foregone gains, prospect theory implies that the former will be more heavily weighted by households in their consumption decision. In this framework, households know the amount of opportunity costs, but simply attach less weight to them compared to out-ofpocket costs.

A second difference between implicit and explicit costs of housing consumption is related to their salience. Opportunity costs are hardly observable, while interest payments can clearly be seen by households. Differences in salience might therefore explain as well why opportunity costs of housing consumption have less mental impact than explicit costs. But in this case, households basically underestimate the amount of opportunity costs rather than underweight them.

Whether opportunity costs are underweighted or underestimated, both mechanisms imply a larger role for explicit costs. By adopting the user costs approach of housing and dividing user costs into out-of-pocket costs and opportunity costs, it becomes possible to empirically estimate if and to what extent opportunity costs are underweighted in housing consumption. For this, section 2.2 will provide a formal relationship between housing consumption and user costs, whereas section 2.3 presents the empirical strategy for estimating the relative weight of opportunity costs. 


\subsection{Modelling housing consumption}

The empirical model that I estimate in section 4 is based on a rather simple theoretical model of housing demand. In this model, the individual demand function for housing is derived from optimizing a Stone-Geary utility function subject to a given budget constraint:

$$
\begin{array}{rl}
\max _{h, x} & u=\left(h-h_{\min }\right)^{\delta} x^{1-\delta} \\
\text { s.t. } & b=w h+p_{x} x
\end{array}
$$

Utility is derived from housing consumption $h$ and other consumption $x$. The specification in (2.1) implies a unit elasticity of substitution between (supra-minimal) housing services and other goods and services.

Housing consumption $h$ is measured in terms of housing services, i.e., the services that each house yearly delivers to its occupants. This notion is similar to how Hall and Jorgenson (1967) treat the fixed assets of a firm, which are assumed to supply capital services to the firm itself. A standard house is assumed to deliver one unit of housing services. By further assuming that a standard house is equal to the average house in the sample, housing consumption can be made comparable between households by calculating the market value of their houses relative to the mean value of all houses.

In model(2.1), $\mathrm{h}_{\min }$ represents the minimal housing consumption. Total household income $b$ is spent on housing services at user costs $\mathrm{w}$ and other consumption at price $p_{x} . P_{x}$ is set equal to 1 by assumption. Parameter $\delta$ represents the housing preferences of households.

The demand function for housing services that can be derived from model (2.1) is:

$$
h=h_{\min }+\frac{\delta\left(b-w h_{\min }\right)}{w}
$$

Demand for housing services is partly fixed and depends for another part on disposable income $b$ and user costs $w$. It reproduces the stylized fact that the expenditure share of total housing consumption typically falls with rising income. Total disposable household income $b$ is the sum of income from labor, pension or other benefits and capital income. Household capital includes savings and stocks, but also home equity, which is defined as the difference between the market value of the house and the mortgage loan.

The user costs are equal to:

$$
w h=(1-s)(\rho-\pi+k+\lambda) p_{h}
$$


The variable $s$ denotes the fiscal subsidy rate of housing consumption. Parameter $\rho$ is equal to the real interest rate plus a fixed risk premium, and $\pi$ is the expected steady state change in price of the standardized dwelling. The price of a standard house is given by $p_{h}$, and $k$ denotes the yearly costs of depreciation and maintenance. Finally, $\lambda$ denotes the (annualized) transaction costs.

\subsection{Empirical strategy}

For estimating (2.2), I propose the following empirical model2:

$$
\ln h_{i}=\ln \left((1-\delta) f_{i} h_{\min }+\frac{\delta b}{w_{p o c k, i}+\beta w_{o p p, i}}\right)+e_{i}
$$

The minimal housing consumption of household $i$ is equal to the minimal housing consumption $\mathrm{h}_{\min }$ of a one person household multiplied by an equivalence factor $\mathrm{f}_{\mathrm{i}}$. The equivalence factor depends on the size and composition of the household, and intends to correct for scale economies in housing consumption. User costs $w_{i}$ are divided into out-ofpocket costs $w_{p o c k, i}$ and opportunity costs $w_{o p p, i}$, such that $w_{i}=w_{p o c k, i+} w_{o p p, i}$.

Out-of-pocket costs consist of the mortgage interest payments minus the net fiscal subsidy for home owners. Implicit costs are simply the remainder of the user costs. They mainly consist of the foregone gains of housing equity and the annualized costs of depreciation and maintenance. Although maintenance costs are obviously highly explicit and out-of-pocket from time to time, the definition above assumes that within the user cost approach they are viewed as implicit when considered on a monthly or annual basis.

In order to investigate the relative weight of implicit costs, I will estimate a restricted and an unrestricted version of model (2.4). In the restricted model, $\beta$ is set to 1 . This restriction implies that out-of-pocket costs and opportunity cost have the same weights. The estimation results of this model will give us an idea to what extent our simple theoretical model of housing consumption in (2.2) is able to describe actual behavior in the Dutch housing market. In the unrestricted model, $\beta$ will be estimated. If $\beta$ turns out to be significantly different from one, this will provide evidence that opportunity costs are weighted differently in housing consumption.

Model (2.4) can be estimated on the full sample of homeowners in the available database. However, that may well lead to endogeneity in one of the regressors. Disposable income $b$ mostly consists of income from labor, but home equity is also a source of disposable (capital) income. Home equity is defined as the value of the house minus the outstanding mortgage loan. Housing consumption $h_{i}$ is defined as the value of the house relative to the value of the average owner-occupied house. An exogenous shock in house prices will therefore affect

\footnotetext{
${ }^{2}$ The logarithmic transformation generates a highly symmetric distribution of residuals.
} 
both housing consumption and home equity, provided that households do not immediately adjust their housing consumption. As such, disposable income is endogenous if we would estimate the model on the full available sample. However, the home equity of households that bought a home in the year of sampling is not affected by an exogenous change in the market value of their newly bought property. For them, the equity invested in their home comes from savings or from profits realized from selling their previous home. Their income from home equity is therefore exogenous. To avoid endogeneity, I will thus restrict the sample to households that bought a house in the year of sampling. 


\section{Data and descriptive statistics}

The database WoON $2009^{3}$ is a representative cross-section of about 70000 Dutch households. The database aims at providing information to policymakers about the various determinants of housing demand and living conditions in the Netherlands. Part of the data is administrative (particularly household income), but most data are derived from questionnaires sent out between September 2008 and May 2009. After selecting households that bought a home in the year of sampling and removing a small number of outliers, 1720 households remain. Below I will explain all variables and parameters underlying model (2.4).

Housing consumption $\boldsymbol{h}$ is the dependent variable based on the value of the house. The market value of the home in the database comes from an administrative source. The so called WOZ value of the house, upon which several local taxes are based, is determined by the municipality in which a house is located. But some of the explanatory variables also depend on the value of the house. As the market value is ultimately a stochastic variable, the error terms of the stochastic exogenous variables are most likely correlated with the error term of the dependent variable. I avoid this by taking the reported purchase price of the house as the measure for housing consumption. The purchase price and the WOZ value are obviously highly correlated, although in some cases large differences between the two exist. I excluded a little over 100 observations where the WOZ value and the purchase price differ by more than $50 \%$. Finally, by multiplying purchase prices by 0.996 I rescaled purchase prices in such a way that their mean is equal to the mean of the WOZ values. This has no effect on the estimation results, but it facilitates the interpretation of the parameter estimates.

The minimal housing consumption $\boldsymbol{h}_{\min }$ of a household depends on its size and composition. Because of economies of scale, minimal housing consumption does not increase proportionally with the number of persons. To correct for this, I use the equivalence factor $\boldsymbol{f}$ as used by Statistics Netherlands. It is based on the following formula:

$$
f_{i}=\sqrt{\left(A_{i}+0.8 C_{i}\right)}
$$

$A$ is the number of adults and $C$ is the number of children. If I simply use the number of persons for the size of a household in the regression, this significantly affects the parameter estimates for $\boldsymbol{h}_{\min }$ and $\delta$, but it has no significant effect on the estimated value of $\beta$.

As mentioned earlier, disposable income $\boldsymbol{b}$ is the sum of income from labor, pension or other benefits and capital income. Household capital includes savings and stocks, but also home equity, which is defined as the difference between the market value of the house and the mortgage loan. The nominal capital income rate is imputed and set at $4 \%$ of the value of

\footnotetext{
${ }^{3}$ The collection of data and the survey is repeated every three years. WoON 2012 was delivered in 2013 and was not yet accessible while the analyses in this paper were being carried out.
} 
total capital. ${ }^{4}$ This income is taxed at a flat rate of $30 \%$. In the Netherlands, home equity is exempted from capital taxation, but I account for this fiscal subsidy in the calculation of the net user costs of housing. All variables used in the calculation of disposable income are from administrative sources, except for the value of the mortgage. To correct for outliers, I have removed a small number of households that report a mortgage loan larger than $150 \%$ of the value of their home.

Parameter $\rho$ in (2.3) is set at 5\% for all households. I assume a real interest rate of $2 \%$ and a risk premium of $3 \%$. The expected real change in the price of a standardized dwelling $\pi$ is assumed to be $1 \%$. This is consistent with a long term economic growth rate of $1.7 \%$ per year combined with a long term supply elasticity of 0.65 . Yearly costs of depreciation and maintenance $k$ are assumed to be equal to $1.5 \%$. The (annualized) transaction $\cos t$ s $\lambda$ are set at $0.25 \%$. Finally, the price of a standard house is equal to 295 thousand euro. In the absence of fiscal subsidy, the user costs of a standard house would then be equal to 16.9 thousand euro, $5.75 \%$ of the value of a house..$^{5}$ This rate is very close to the long run relation between prices and rents found by Ambrose et al. (2013) for houses in Amsterdam from 1650 through 2005.

The net user cost of a standard house, i.e. the price for one unit of housing consumption, is 12 thousand euro. The average fiscal subsidy rate of housing consumption in the sample is hence almost 7 thousand euro, or 29 percent of the gross user costs. This fairly high subsidy is due to the low taxation of imputed rent on the one hand (less than $1 \%$ of the value of the house) and the full deductibility of mortgage interest on the other. On top of that, home equity is exempted from capital income taxation. I calculated the fiscal subsidy for each household using their actual interest mortgage payments, the market value of their homes and their mortgage loans. I further use a uniform tax rate of $47 \%{ }^{6}$ for calculating the fiscal advantage due to interest deductibility and an effective tax rate of $1.2 \%$ of home equity for calculating the fiscal benefits of its fiscal exemption.

As mentioned in 2.3, out-of-pocket costs $\boldsymbol{w}_{\text {pock }}$ consist of the mortgage interest payments minus the net fiscal subsidy for home owners. ${ }^{7}$ Most Dutch households pay their interest on a monthly basis, and also the fiscal subsidy is usually (provisionally) paid out each month. I therefore subtract the subsidy from the out-of-pocket expenses. Implicit costs $\boldsymbol{w}_{\text {opp }}$ are simply the remainder of the user costs. To calculate the out-of-pocket and opportunity costs per unit of consumption, I simply divide these costs by the level of consumption $\mathrm{h}_{\mathrm{i}}$. Because some respondents report unrealistically high interest payments, I remove a small number of

\footnotetext{
${ }^{4}$ Setting this rate a $3 \%$ or $5 \%$ has only a very small effect on the estimation results below.

${ }^{5}$ Increasing or decreasing gross user costs by $1 \%$-point again has only a very small effect on the estimation results.

${ }^{6}$ At this rate the total fiscal subsidies in the database match the macro-economic data on fiscal subsidies in 2005.

${ }^{7}$ By excluding maintenance from out-of-pocket cost, I run the risk of underestimating these. The database I use contains some (categorized) information on the costs of maintenance and rebuilding carried out in the year previous to the survey. However, it is unknown whether these were paid in cash or financed by a loan. In the Netherlands, it is common practice though to finance larger construction jobs by a mortgage loan, particularly at the time when people buy another home. In general, interest on these loans is tax deductible, which makes these loans relatively attractive. Therefore, I expect a minor effect of ignoring out-of-pocket maintenance costs. As an indirect robustness check, I ran the regressions in the next section separately for the group of households with low (<2500 euro) and high (2500 euro and higher) reported maintenance cost. I found no significant differences in any of the estimated demand parameters.
} 
households with implied mortgage interest rates larger than 10\%.

Table 3.1 shows some descriptive statistics of the variables I use in estimating model (2.4).

Table 3.1 Descriptive statistics

\begin{tabular}{|c|c|c|c|c|c|}
\hline Variable & Mean & Median & $\begin{array}{l}\text { Standard- } \\
\text { deviation }\end{array}$ & Minimum & Maximum \\
\hline Housing consumption $(h)$ & 0.86 & 0.76 & 4.38 & 0.17 & 5.05 \\
\hline \multirow[t]{2}{*}{ Equivalence factor $(f)$} & 1.43 & 1.37 & 3.30 & 1 & 4.77 \\
\hline & \multicolumn{2}{|c|}{ x 1000 euro } & & & \\
\hline Disposable income $(b)$ & 43.4 & 38.8 & 230 & 0.2 & 382 \\
\hline Out-of-pocket user cost per unit of housing consumption ( $\left.w_{\text {pock }}\right)$ & 6.94 & 7.20 & 31.8 & 0 & 17.0 \\
\hline Opportunity cost per unit of housing consumption ( $w_{\text {opp }}$ ) & 5.11 & 5.01 & 52.9 & -13 & 17.1 \\
\hline
\end{tabular}

Despite removing some outliers in advance, we still observe some extreme values for notably the opportunity costs. This is due to households reporting mortgage interest rates close to $10 \%$ in combination with large mortgage loans. In some cases, this leads to out-of-pockets costs larger than the users costs (and hence, by my definition, to negative opportunity costs). On average, out-of-pocket costs are close to 7000 euro's per unit of housing consumption and opportunity costs a little over 5000 euro's. These variables show a substantial amount of variation across the sample. This dispersion arises because of differences in the loan to value ratio and in differences in the actual interest payments. Differences between mean and median values are rather small. 


\section{Results and discussion}

\subsection{Estimation results}

The analysis shows that opportunity costs are substantially underweighted in the Dutch housing market. Dutch homeowners attach approximately twice as much weight to the outof-pocket costs of their housing consumption compared to the opportunity costs associated with this. Table 4.1 shows the results from estimating model (2.4) by means of ordinary least squares. In the unrestricted model, $\beta$ is estimated at 0.49 . A Wald-test on the hypothesis that $\beta=1$ shows that this hypothesis should be rejected. Furthermore, the unrestricted model produces a much better result than the model with the restriction $\beta=1$ according to a standard F-test. Despite its simplicity, the restricted model performs rather well in explaining the housing consumption of Dutch homeowners. Yet, the observed variation in housing consumption is much better explained by allowing the weight of opportunity costs to be different from the weight of out-of-pocket costs. Apparently, households are led much more by out-of-pocket costs than by the true economic costs of their housing consumption.

Table 4.1 Estimation results model (2.4)

\begin{tabular}{|c|c|c|c|c|}
\hline Model & $\mathrm{h}_{\min }$ & $\delta$ & $\beta$ & $\begin{array}{l}\text { R-squared } \\
\text { adjusted }\end{array}$ \\
\hline Model with restriction $\beta=1$ & $\begin{array}{r}0.30 \\
(0.01)\end{array}$ & $\begin{array}{r}0.11 \\
(0.01)\end{array}$ & 1 & 0.36 \\
\hline Unrestricted model & $\begin{array}{r}0.23 \\
(0.01)\end{array}$ & $\begin{array}{r}0.11 \\
(0.01)\end{array}$ & $\begin{array}{r}0.49 \\
(0.02)\end{array}$ & 0.48 \\
\hline
\end{tabular}

\subsection{Alternative explanations}

Despite the strong statistical evidence regarding the weight of opportunity costs in estimating model (2.4), we cannot be sure that the underweighting of opportunity costs is the sole driver of the regression results. A number of alternatives might explain these results as well. First, the estimated low weight in model (2.4) can be the result of an incorrect specification of the model. Ignoring credit constraints is one way to obtain a falsely low estimation of the weight of opportunity costs. The low weight of opportunity costs implies that households with private equity spend a larger share of their total disposable income on housing consumption than households that are fully dependent on mortgage credit. Still, this pattern could also be the result of credit rationing. Credit rationed households will not be able to optimize their housing consumption. But households with sufficient equity will be able to compensate the restriction on their optimal housing consumption by using their 
private funds to finance their homes.

Second, ignoring the age of household members might also distort the estimation results. Perhaps the optimal housing consumption is directly related to age. For instance, the desire to have a (larger) garden may increase with age, at least up to a certain point. Since age and equity are correlated, the positive relationship between equity and the share of housing costs in disposable income might just be explained by age-dependent preferences.

Third, housing preferences can directly depend on home equity as well, for instance through habit formation. An exogenous rise in house prices might affect the desired levels of housing consumption of incumbent homeowners buying a new house. Incumbent Dutch households that bought a home in 2008 have most likely obtained a substantial profit on selling their previous home. In the Netherlands, real house prices have increased almost continuously since the mid-80s. Under the assumption of habit formation, these households will spend a larger share of their (capital) income on housing consumption. They got used to living in a house in a higher price range and are simply not willing to lower their housing consumption in accordance with their initial preferences.

Fourth, within a cross-section of households a positive relationship between equity and housing consumption could also make sense from a life-cycle perspective. If ageing households dissave from capital they built up earlier in life, a larger share of their disposable income can be spent on consumption, including housing.

Finally, mental accounting may explain why more equity is associated with a higher share of housing costs in disposable income. Shefrin and Thaler (1998) argue that the marginal propensity to consume out of current income, current wealth and future income is different. The share of housing expenditures in income from capital may then be significantly different from its share in e.g. labor income.

By adding a number of explanatory variables to model (2.4), I aim to test whether these alternative explanations falsify my results. I have added age class dummies, the loan-toincome ratio and a dummy variable for incumbency. I have also split up capital income into income from housing equity and from other private funds. Obviously, the cross-sectional nature of my data limits the scope for properly testing the alternative explanations, particularly the one related to the life-cycle perspective. The analyses below should therefore be seen as a first robustness check of my main empirical results.

For testing the alternative explanations, I first extend the base model by decomposing disposable income $b$. First, income out of labor, pension or welfare is denoted by $b_{w}$. Imputed capital income from savings and other financial assets is labeled $b_{s}$. Finally, imputed income from home is denoted by $b_{h}$. Our empirical model then becomes:

$$
\ln h_{i}=\ln \left((1-\delta) f_{i} h_{\min }+\frac{\delta\left(b_{w, i}+b_{s, i}+\alpha_{i} b_{h, i}\right)}{w_{p o c k, i}+\beta w_{o p p ~}, i}\right)+e_{i}
$$


By adding parameter $\alpha$, I introduce another mechanism through which higher home equity could lead to higher housing consumption. If the marginal propensity to consume from $b_{h}$ is higher than the propensity to consume from $b_{w}$, more home equity will lead to a relatively higher housing consumption as well. In that case, it is not related to a lower weight of opportunity costs, but merely due to different consumption patterns. As a robustness check of the results in the previous section, the inclusion of parameter $\alpha$ is therefore relevant.

Opportunity costs and income from home equity might, however, be highly correlated. Both are directly related to how much households invest of their own capital into their houses. However, opportunity costs have an additional source of empirical variation. For a given level of home equity, out-of-pocket costs may differ because in practice households pay different mortgage interest rates. Since opportunity costs are the complement of out-ofpocket costs, we can observe some variation in opportunity costs that is not related to the amount of home equity. In fact, the sample correlation coefficient between $w_{\text {opp }}$ and $b_{h}$ is equal to 0.5 .

Table 4.2 below presents the results of estimating the various models I discuss in this section. The results from estimating model (4.1) show that $\alpha$ is significantly larger than one and the estimated value of $\beta$ goes up, though it still remains significantly less than one. At first glance, allowing for differences in the propensity to consume from the various sources of income seems appropriate. Yet it does not reject the hypothesis that opportunity costs are significantly underweighted.

For testing whether credit constraints affect my results, I estimate the following model:

$$
\ln h_{i}=\ln \left((1-\delta) f_{i} h_{\min }+\frac{\delta\left(b_{w, i}+b_{s, i}+\left(\alpha+\gamma L T I_{i}\right) b_{h, i}\right)}{w_{p o c k, i}+\beta w_{o p p ~}, i}\right)+e_{i}
$$

As I have no data on actual credit constraints, I approximate these by the loan to income ratio ( $L T I)$. Households with a low $L T I$ were most likely less credit constrained than households with high LTI. If credit constraints explain why more equity is associated with higher housing consumption, we would expect that household with a high LTI spend a larger part of their income from home equity on housing consumption. In terms of model (4.2), we would expect that under the hypothesis of credit rationing, $\alpha$ is equal or close to one and $\gamma$ is significantly positive.

As the third column in Table 4.2 shows, the inclusion of the loan-to-income ratio in model (4.2) hardly affects the value of $\beta$ or any of the other estimates. Credit constraints apparently do not affect the main results from section 4.1.

To test whether age affects my main results, I classify households into three age groups, according to the age of the principal household member: young ( $<30$ years), middle-aged (between 30 and 60) and old ( $>60$ ). These age classes are denoted by three dummy 
variables, respectively $D_{y}, D_{m}$ and $D_{0}$. The model then becomes:

$$
\ln h_{i}=\ln \left((1-\delta) f_{i}\left(h_{\min }+\lambda_{1} \mathrm{D}_{m}+\lambda_{2} \mathrm{D}_{o}\right)+\frac{\left(\delta+\lambda_{3} \mathrm{D}_{m}+\lambda_{4} \mathrm{D}_{o}\right)\left(b_{w, i}+b_{s, i}+\alpha_{i} b_{h, i}\right)}{w_{p o c k, i}+\beta w_{o p p ~}, i}\right)+e_{i}
$$

From the fourth column in Table 4.2 we can conclude that the inclusion of the age dummies also does not affect the main results.

The role of habit formation can approximately be evaluated by including a dummy variable $D_{\text {own }}$ that equals one if the household previous residence was owner-occupied as well. If $\psi_{1}$ in model (4.4) turns out to be significantly positive, incumbent homeowners exhibit a higher minimal consumption level than new homeowners. A significantly positive estimate for $\psi_{2}$ will suggest a higher propensity to consume from home equity for incumbent homeowners.

$$
\ln h_{i}=\ln \left((1-\delta) f_{i}\left(h_{\min }+\psi_{1} D_{o w n, i}\right)+\frac{\delta\left(b_{w, i}+b_{s, i}+\left(\alpha+\psi_{2} D_{o w n, i}\right) b_{h, i}\right)}{w_{p o c k, i}+\beta w_{o p p, i}}\right)+e_{i}
$$

If we compare he results from estimating model (4.4) with the other models in Table 4.2, we see that it is actually the ownership of the previous home that explains why a higher share of own funding is associated with higher supra-minimal housing consumption rather than differences in the propensity to consume from the various sources of income. In fact, the parameter estimate for $\alpha$ is not significantly different from 1 in model (4.4). This may suggest that habit formation has indeed played a role for Dutch households. Nevertheless, this finding still does not reject the hypothesis of underweighting of opportunity costs in housing consumption.

Finally, to investigate whether mental accounting makes a difference in the empirical results, I allow the propensity to consume from income derived from savings and financial assets to be different from the other income sources as well. This leads to the following model:

$$
\ln h_{i}=\ln \left((1-\delta) f_{i} h_{\min }+\frac{\delta\left(b_{w, i}+\theta b_{s, i}+\alpha b_{h, i}\right)}{w_{p o c k, i}+\beta w_{o p p ~}, i}\right)+e_{i}
$$

As the last column in Table 4.2 shows, the parameter estimate for $\theta$ in model (4.5) is not significantly different from 1 . Mental accounting, albeit highly indirectly approximated, thus does not seem to affect my main empirical results from section 4.1 as well.

In conclusion, the data clearly support the hypothesis that opportunity costs are substantially underweighted. Our empirical analysis of housing consumption confirms the findings of experimental research by Thaler (1980). Still, I do not find evidence for a complete neglect of opportunity costs, such as in Frederick et al. (2009). By and large, opportunity costs only weigh in for about 50 to 65 percent of their actual value in the reallife economic act of buying a home. 
Table 4.2 Estimation results alternative models

\begin{tabular}{|c|c|c|c|c|c|c|c|}
\hline & & $(2.4)$ & (4.1) & $\begin{array}{r}\text { Model } \\
(4.2)\end{array}$ & $(4.3)$ & $(4.4)$ & (4.5) \\
\hline \multirow[t]{2}{*}{ Minimal housing consumption } & $h_{\min }$ & $0.23^{* *}$ & $0.25^{\star *}$ & $0.25^{\star *}$ & $0.28^{* *}$ & $0.24^{* *}$ & $0.25^{\star *}$ \\
\hline & & $(0.01)$ & $(0.01)$ & $(0.01)$ & $(0.02)$ & $(0.01)$ & $(0.01)$ \\
\hline \multirow[t]{2}{*}{ Housing consumption propensity } & $\delta$ & $0.11^{* *}$ & $0.11^{* *}$ & $0.11^{* *}$ & $0.08^{* *}$ & $0.10^{* *}$ & $0.11^{* *}$ \\
\hline & & $(0.01)$ & $(0.01)$ & $(0.01)$ & $(0.01)$ & $(0.01)$ & $(0.01)$ \\
\hline \multirow[t]{2}{*}{ Weight of opportunity costs } & $\beta$ & 0.49 ** & $0.62^{\star *}$ & $0.63^{\star *}$ & $0.62^{\star *}$ & $0.63^{* *}$ & $0.62^{\star \star}$ \\
\hline & & $(0.02)$ & $(0.03)$ & (0.03) & $(0.03)$ & (0.03) & $(0.03)$ \\
\hline \multirow[t]{2}{*}{ Housing consumption from home equity } & $\alpha$ & & $3.43^{\star *}$ & $3.60^{* *}$ & $3.27^{* *}$ & $1.09^{*}$ & $3.41^{* *}$ \\
\hline & & & $(0.35)$ & $(0.45)$ & $(0.37)$ & $(0.48)$ & $(0.36)$ \\
\hline \multirow[t]{2}{*}{ Impact of LTI on consumption from home equity } & $Y$ & & & -0.05 & & & \\
\hline & & & & 0.08 & & & \\
\hline \multirow[t]{2}{*}{ Effect of middle-aged on minimal consumption } & $\lambda_{1}$ & & & & $-0.05^{*}$ & & \\
\hline & & & & & $(0.02)$ & & \\
\hline \multirow[t]{2}{*}{ Effect of old-aged on minimal consumption } & $\lambda_{2}$ & & & & 0.01 & & \\
\hline & & & & & $(0.05)$ & & \\
\hline \multirow{2}{*}{ Effect of middle-aged on supra-minimal consumption } & $\lambda_{3}$ & & & & $0.03^{* *}$ & & \\
\hline & & & & & $(0.01)$ & & \\
\hline \multirow[t]{2}{*}{ Effect of old-aged on supra-minimal consumption } & $\lambda_{4}$ & & & & 0.02 & & \\
\hline & & & & & $(0.01)$ & & \\
\hline \multirow[t]{2}{*}{ Effect of incumbency on minimal consumption } & $\psi_{1}$ & & & & & $0.03^{* *}$ & \\
\hline & & & & & & $(0.01)$ & \\
\hline \multirow[t]{2}{*}{ Effect of incumbency on supra-minimal consumption } & $\psi_{2}$ & & & & & $3.06^{* *}$ & \\
\hline & & & & & & $(0.55)$ & \\
\hline \multirow[t]{2}{*}{ Housing consumption from other capital income } & $\theta$ & & & & & & $1.24^{* *}$ \\
\hline & & & & & & & $(0.28)$ \\
\hline \multicolumn{2}{|l|}{ Adjusted $\mathrm{R}^{2}$} & 0.48 & 0.51 & 0.51 & 0.52 & 0.52 & 0.51 \\
\hline \multicolumn{8}{|c|}{$\begin{array}{l}\text { Note: standard errors in parentheses. } 1720 \text { observations were used in all models. } \\
\text { * estimated parameters differ significantly from } 0 \text { at less than } 5 \% \text { significance level. } \\
\text { ** estimated parameters differ significantly from } 0 \text { at less than } 1 \% \text { significance level. }\end{array}$} \\
\hline
\end{tabular}




\section{Conclusions}

Human decision makers attach less weight to opportunity costs, but they do not fully ignore them. When people buy houses, the foregone revenues of the private equity they invest only weigh in for about 50 to 65 percent of their actual value. Experimental research highlighted this phenomenon before, but I show that also in major, real life economic decision making the underweighting of opportunity costs is indeed significant. In practice, people apparently do not obey the normative implications of standard economic theory, which tells us that outpocket costs and opportunity costs should be treated equally.

Although opportunity costs are relevant in virtually every economic decision, often it is not easy to know exactly what they are. I have argued that housing consumption offers the opportunity to analyze the weight of opportunity costs. Another area to explore this kind of research might be the car market. Do people who finance their car without a loan underweight the opportunity costs of investing their own money as well? And do we see a difference in the 'consumption' of cars between old and new ones? New cars normally have low out-of-pocket user costs, but high implicit costs because of significant depreciation. For older cars, it is usually the opposite: high out-of-pocket maintenance costs versus low depreciation. Correcting for quality, does this difference between old and new cars bias the demand for cars towards new ones?

The actual cause of the underweighting of opportunity costs provides another research opportunity. Is it related to loss aversion, where out-of-pocket costs have larger mental impact than foregone revenues on equity? Or can underweighting be attributed to the lack of salience of opportunity costs? In case of the former, policy implications are virtually absent. The underweighting is then merely due to prospect-theoretic preferences. But if it is a matter of underestimating the true economic costs, perhaps better information on the opportunity costs when people buy a home could help people make better decisions. Hoskin (1983) has shown that explicit information on opportunity costs can indeed make a difference to the economic decision that people make.

Explicit information on the opportunity costs of housing consumption even can have some positive effects on macro-economic stability. In a housing market boom, incumbent homeowners see their home equity grow. When they move to another home, their higher equity suppresses out-of-pocket costs and pushes demand for properties even further if households indeed underestimate the true user costs of their new homes. A better awareness of the actual user costs of housing consumption may then, to some extent obviously, decrease the risk of a self-reinforcing pricing bubble on the housing market. Many governments feel the need to warn households for the high costs of borrowing, but it might also make sense to tell people that using their own resources comes at a price as well. I certainty acknowledge the practical difficulties of implementing such a policy, yet it may eliminate the potentially unwanted bias resulting from underestimating actual housing costs. 


\section{References}

Ambrose, B. W., Eichholtz, P. and Lindenthal, T., 2013. House Prices and Fundamentals: 355 Years of Evidence. Journal of Money, Credit and Banking, 45 (2/3), 477-491.

Ashraf, N., Camerer, C., and Loewenstein, G., 2005. Adam Smith, Behavioral Economist. Journal of Economic Perspectives 19 (3), 131-145.

Frederick, S., Novemsky, N., Wang, J., Dhar, R., and Nowlis, S., 2009. Opportunity cost neglect. Journal of Consumer Research 36 (4), 553-561.

Hall, R. and Jorgenson, D., 1967. Tax Policy and Investment Behavior. American Economic Review 57 (3), 391-414.

Hoskin, R., 1983. Opportunity Cost and Behavior. Journal of Accounting Research 21(1), 7895.

Poterba, J., 1984. Tax Subsidies to Owner-Occupied Housing: An Asset-Market Approach. Quarterly Journal of Economics 99 (4), 729-752.

Shefrin, H. and Thaler, R., 1988. The behavioral life-cycle hypothesis, Economic Inquiry, 26 (4), 609-43.

Stango, V. and Zinman, J., 2009. What Do Consumers Really Pay on Their Checking and Credit Card Accounts? Explicit, Implicit,and Avoidable Costs. American Economic Review 99 (2), Papers and Proceedings of the One Hundred Twenty-First Meeting of the American Economic Association, 424-429.

Thaler, R., 1980. Towards a positive theory of consumer choice. Journal of Economic Behavior and Organization 1, 39-60. 

Publisher:

CPB Netherlands Bureau for Economic Policy Analysis

P.O. Box 80510 | 2508 GM The Hague

$\mathrm{T}$ (070) 3383380

November 2015 | ISBN 978-90-5833-706-1 